\title{
Cystic Fibrosis testing among Arab-Americans
}

\author{
Sainan Wei, $P h D^{1}$, Gerald L. Feldman, $M D, P h D^{2,3}$, Kristin G. Monaghan, $P h D^{1}$
}

\begin{abstract}
Purpose: Limited data regarding the cystic fibrosis carrier frequency and mutation detection rate is available for Arab-Americans. We retrospectively determined the frequency of carriers among Arab-Americans undergoing preconception and prenatal carrier screening in our laboratories. Methods: Between October, 2001 and June, 2005, we performed carrier screening on 805 Arab-Americans, testing for at least the original 25 mutations recommended by the American College of Medical Genetics. We compared our results to previously published studies among Arabic cystic fibrosis patients. We also performed diagnostic testing on seven individuals. Results: Seven carriers were identified, with an observed carrier frequency of 1 in 115 . The most common mutation we identified was $\mathrm{W} 1282 \mathrm{X}$ ( $57 \%$ of the mutations detected), followed by $\Delta \mathrm{F} 508$ and $\mathrm{R} 117 \mathrm{H}$. Three of 7 patients with a known or suspected diagnosis had two identifiable mutations, including 1548delG, $\Delta$ F508, W1282X, 2789 + 5G $>$ A and $\mathrm{R} 170 \mathrm{H}$. Conclusion: The current recommended carrier screening panel includes only six mutations reported among Arabic cystic fibrosis patients, accounting for $37.1 \%$ of the mutations identified among this group. The addition of 1548delG, I1234V, H139L and 4010del4 as part of an extended screening panel would increase the detection rate to 66.3\%, similar to the mutation detection rates in other races/ethnic groups. Genet Med 2006:8(4):255-258.
\end{abstract}

Key Words: cystic fibrosis, Arab-American, carrier screening

Since the cloning of the cystic fibrosis (CF) gene in 1989, 1,2,3 more than 1,000 mutations have been identified. ${ }^{4}$ Most are extremely rare, often reported in only one family. In 2001, the American College of Medical Genetics (ACMG) and American College of Obstetricians and Gynecologists (ACOG) recommended CF carrier screening using a 25-mutation panel for Caucasians who are pregnant or considering pregnancy. They also recommended that testing be made available to individuals in other races and ethnic groups with a lower CF carrier frequency. ${ }^{5}$ The original 25 mutations were chosen because they had a frequency of $\geq 0.1 \%$ in the pan-ethnic U.S. population. ${ }^{5}$ This panel was modified in 2004 to 23 mutations. ${ }^{6}$ Reliable data exist for the carrier frequency and mutation detection rates among Caucasians, African-Americans, and Hispanic-Americans. This is essential for accurate interpretation and risk assessment used by patients to make informed decisions regarding reproductive options. ${ }^{6,7}$ However, there is limited epidemiological data on the frequency of CF and prevalent mutations among Arabic CF patients. Furthermore, there are no published reports describing the outcome of CF carrier screening among Arab-Americans. Detroit, Michigan has one of the largest Arab-American populations. Arab-Americans

\footnotetext{
From the ${ }^{1}$ Medical Genetics, Henry Ford Hosp, Detroit, MI; ${ }^{2}$ Detroit Medical Center-University Laboratories, Detroit, MI; ${ }^{3}$ Molecular Medicine and Genetics, Pediatrics and Pathology, Wayne State University, Detroit, MI.

Kristin G. Monaghan, PhD, FACMG, Department of Medical Genetics, Henry Ford Hospital, 2799 West Grand Boulevard; CFP 466 Detroit, Michigan 48202

Submitted for publication November 17, 2005.

Accepted for publication January 19, 2006.
}

DOI: 10.1097/01.gim.0000214453.74456.f3 comprise the third largest population tested in our laboratories, after Caucasians and African-Americans. We report our experience with CF carrier screening among Arab-Americans and compare our results to previously published studies among Arabic CF patients.

\section{MATERIALS AND METHODS}

\section{Patient population}

Since January, 1990, we performed diagnostic testing on seven Arab-American patients, six with a suspected diagnosis of $\mathrm{CF}$ and one with congenital bilateral absence of the vas deferens (CBAVD) (Table 1). Between October, 2001 and June, 2005, a total of 805 individuals of self-reported Arab-American ancestry (including Arabic, Chaldean, Iraqi, Syrian, Jordanian, and Lebanese) underwent CF carrier screening at our institutions. The indications for testing were population carrier screening for 757 (94\%) individuals. The remaining 48 patients included in this report were tested for an unspecified indication, assumed to be carrier screening because they were pregnant females and the test was ordered by an obstetrician or nurse midwife. Of the patients tested, 784 (97\%) were female and $21(3 \%)$ were male. Five couples were tested in a sequential manner, with the remaining 16 tested simultaneously.

\section{Molecular CF mutation analysis}

DNA was extracted using either the PureGene kit (Gentra) or QIAmp DNA Blood Mini Kit (Qiagen) according to the conditions specified by the manufacturers. Several methods were used for CF mutation analysis throughout this time period by the two laboratories; all methods used for carrier 
Table 1

Summary of patients tested for diagnostic purposes

\begin{tabular}{|c|c|c|c|c|}
\hline Ethnicity & Age & Clinical findings & Method used for CF testing & Genotyping results $^{a}$ \\
\hline Arabic & 4 days & $\begin{array}{l}\text { Suspected diagnosis, } \\
\text { meconium ileus }\end{array}$ & Reverse dot-blot ${ }^{b}$ & $\Delta \mathrm{F} 508 / \mathrm{W} 1282 \mathrm{X}$ \\
\hline Arabic & 8 years & $\begin{array}{l}\text { Mild obstructive lung disease, } \\
\text { moderate persistent } \\
\text { asthma and allergic rhinitis }\end{array}$ & Reverse dot-blot ${ }^{b}$ & Negative \\
\hline Arabic & 12 years & $\begin{array}{l}\text { Borderline sweat test, chronic } \\
\text { sinusitis, nasal polyps }\end{array}$ & Reverse dot-blot ${ }^{b}$ & Negative; 5T/9T \\
\hline Arab-American & 18 months & $\begin{array}{l}2 \text { positive sweat tests; known } \\
\text { affected }\end{array}$ & $\begin{array}{l}\text { Heteroduplex analysis with } \\
\text { sequencing }\end{array}$ & 1548delG homozygous \\
\hline Arab-American/European & 5 years & $\begin{array}{l}\text { Asthma, recurrent } \\
\text { pneumonia, possible } \\
\text { clubbing }\end{array}$ & $\begin{array}{l}\text { Heteroduplex analysis and } \\
\text { sequencing }\end{array}$ & Negative \\
\hline Arabic & 48 years & CBAVD & $\begin{array}{l}\text { Heteroduplex analysis and } \\
\text { sequencing }\end{array}$ & $\begin{array}{l}2789+5 \mathrm{G}>\mathrm{A} / \mathrm{R} 170 \mathrm{H} \\
(7 \mathrm{~T} / 7 \mathrm{~T})\end{array}$ \\
\hline Arab-American & 34 years & Pancreatitis, chronic cough & $\begin{array}{l}\text { Heteroduplex analysis and } \\
\text { sequencing }\end{array}$ & Negative (7T/7T) \\
\hline
\end{tabular}

${ }^{a}$ Prior to 2001, polyT analysis was only performed when specifically requested by the ordering physician.

${ }^{b}$ Refers to method $\mathrm{D}$ in the text.

${ }^{c}$ Refers to method $\mathrm{A}$ in the text.

screening included the original 25 mutations recommended by ACOG/ACMG.

\section{Method A}

Prior to October, 2001, CF studies were performed by PCR amplification followed by heteroduplex analysis (exons 3, 4, 5, 7, 10,11 and 19) on a mutation detection enhancement (MDE) gel and restriction fragment length polymorphisms (RFLP) analysis for specific mutations. This method was used only for diagnostic testing and was not used for any preconception or prenatal carrier screening. DNA sequencing was used to confirm mutations identified by heteroduplex analysis when no confirmatory RFLP was available. Mutations tested were: 297-3C $>$ T, G85E, 394delTT, P67L, 405 + 3A >C, E92X, 556delA, 557delT, I148T, R117H, A120T, Y122X, 621 + 1G>T, G178R, 711 + 1G>T, R297Q, Y301C, R347P, R334W, $\Delta \mathrm{F} 311,1078$ delT, 1138insG, 1154insTC, I1336K, A455E, $\Delta$ F508, $\Delta$ I507, Q493X, V520F, 1548delG, 1609delCA, 1677delTA, 1717-1G > A, G551D, R553X, R560T, G542X, G551S, S549N, S549R, $1891+1 \mathrm{G}>\mathrm{A}, 2189$ delA, $2789+5 \mathrm{G}>\mathrm{A}, 3120+1 \mathrm{G}>\mathrm{A}, 3659$ delC, R1162X, S1235R, I1234V, 3849 + 10kbC > T, W1282X and N1303K. Additional mutations would theoretically also be detected by heteroduplex analysis.

\section{Method B}

Between October, 2001 and August, 2002, 115 individuals were screened using a combination of the CF OLA v2.0 kit (Celera Diagnostics/Abbot Diagnostics/Applied Biosystems) to test for 31 CF mutations including additional nine mutations (Q493X, V520F, S549N, S549R, 3849 + 4A $\rightarrow$ G, 3905insT, Y122X, R347H, and $2183 \mathrm{AA} \rightarrow \mathrm{G}$ ) that were not in the ACMG recommended panel, a laboratory-developed heteroduplex analysis (exon 4 and 13) and RFLP analysis for three additional recommended muta- tions, but not included in CF OLA v2.0 (I148T, 2184delA, and $3120+1 \mathrm{G} \rightarrow \mathrm{A}$, respectively).

\section{Method C}

Between September, 2002 and June, 2005, 645 individuals were tested using the CF OLA v3.0 ASR kit, which includes all 25 recommended mutations (eliminating the need for additional testing using alternative methods) in addition to seven other CF mutations (S549N, S549R, V520F, 3876delA, 394delTT, 3905insT, and $\mathrm{R} 347 \mathrm{H}$ ). Detection of all OLA products was performed using an ABI 3100 Genetic Analyzer (capillary sequencer) followed by analysis using GeneScan and Genotyper software (Applied System).

\section{Method D}

Forty-five individuals were tested using the INNO-LiPA CFTR Assay System (reverse dot blot hybridization). This assay uses PCR-derived amplicons, which hybridize to two test strips that contain 74 probes and four control lines. Included on the strips are the mutant and wild-type sequences of 36 immobilized targets covering ACMG recommended mutations and 11 additional CF mutations (CFTRdele2, 3(21kb), 3272-26A $\rightarrow$ G, 3905insT, S1251N, 3199del6, Q552X, 2183AA $\rightarrow$ G, 394delTT, 2143delT, E60X, $711+5 \mathrm{G} \rightarrow \mathrm{A})$.

Reflex testing for 3199del6 on I148T carriers was done using a laboratory-developed heteroduplex assay. The length of the intron 8 poly $\mathrm{T}$ tract was determined for $\mathrm{R} 117 \mathrm{H}$ carriers using a previously described method. ${ }^{8}$

\section{RESULTS}

We identified a total of seven CF carriers among the 805 Arab-Americans screened, for an overall observed carrier fre- 
quency of $1 / 115(0.9 \%)$. Thirteen I148T carriers were also identified; however, because they did not have 3199del6, they were not considered to be CF carriers in our analysis. ${ }^{9,10} \mathrm{We}$ identified four W1282X carriers, two $\Delta \mathrm{F} 508$ carriers, and one $\mathrm{R} 117 \mathrm{H} / 7 \mathrm{~T}$ carrier who also had I148T but was negative for 3199del6. The overall observed allele frequencies for W1282X, $\Delta \mathrm{F} 508$, and $\mathrm{R} 117 \mathrm{H}$ were $0.25 \%, 0.12 \%$ and $0.06 \%$, respectively.

We identified one positive-positive consanguineous couple through sequential screening; both were W1282X carriers. Fetal testing done by CVS revealed homozygosity for W1282X, and the fetus was predicted to be affected with CF. This pregnancy was terminated after the couple received genetic counseling. Because this couple was tested sequentially and was known to be consanguineous, the W1282X carrier status of the male partner was not included in our calculations to determine carrier frequency in the Arab-American population.

Genotype results for patients tested for diagnostic purposes are summarized in Table 1. Among 6 patients with a known or suspected diagnosis of CF, 2 had 2 identifiable mutations and one carried only one copy of 5T. Two mutations were also identified in an adult male with CBAVD. The mutations identified among this group included 1548delG ( 2 chromosomes), $\Delta$ F508, W1282X, 2789 + 5G $>$ A and R170H (1 chromosome, each).

\section{DISCUSSION}

In this study, a total of 805 individuals of self-reported ArabAmerican ancestry underwent CF carrier screening. We identified seven CF carriers, with an observed carrier frequency of 1 in 115. Compared to other populations, the observed carrier frequency among Arab-Americans is lower than AfricanAmericans and Hispanic-Americans (Table 2).5,6,7

One previously published study estimated the incidence of CF among Arabic children as 1 in 4,243, ${ }^{11}$ representing a carrier frequency of 1 in 33. Although we are unaware of any published data regarding CF population carrier screening among Arab-Americans, several studies have reported the mutation distribution among Arabic CF patients. ${ }^{12,13,14}$ Combin-

Table 2

Summary of carrier frequencies and detection rates among different races and ethnic groups using the 23-mutation ACMG recommended screening panel

\begin{tabular}{lcccc}
\hline Ethnic groups & $\begin{array}{c}\text { Population } \\
\text { carrier } \\
\text { frequency }\end{array}$ & $\begin{array}{c}\text { Detection } \\
\text { rate }\end{array}$ & $\begin{array}{c}\text { Expected } \\
\text { carrier } \\
\text { frequency }\end{array}$ & $\begin{array}{c}\text { Observed } \\
\text { carrier } \\
\text { frequency }\end{array}$ \\
\hline Caucasian & $1 / 25$ & $88 \%$ & $1 / 28$ & $1 / 26$ \\
Hispanic-American & $1 / 58$ & $72 \%$ & $1 / 81$ & $1 / 46$ \\
African-American & $1 / 61$ & $65 \%$ & $1 / 94$ & $1 / 62$ \\
Arabic & $1 / 33$ & $37 \%$ & $1 / 89$ & $1 / 115$ \\
Asian-American & $1 / 94$ & $49 \%$ & $1 / 192$ & $1 / 140$ \\
\hline
\end{tabular}

${ }^{a}$ Unpublished data, 2005. Observed carrier frequencies are not statistically significantly different from expected. ing these studies, a total of 96 CF patients from 93 different Arabic families were analyzed. Among the 93 different families, 26 different mutations were identified with the results summarized in Table 3. Of these mutations, $\Delta \mathrm{F} 508,1548 \mathrm{delG}$, $3120+1 \mathrm{G} \rightarrow \mathrm{A}, \mathrm{I} 1234 \mathrm{~V}, \mathrm{~N} 1303 \mathrm{~K}, \mathrm{~W} 1282 \mathrm{X}, \mathrm{H} 139 \mathrm{~L}$, 4010del4, G115X, $711+1 \mathrm{G} \rightarrow \mathrm{A}$ and S549R are the most common, together accounting for $70 \%$ of CF chromosomes in this population. In addition, a large deletion of exons $17 \mathrm{a}, 17 \mathrm{~b}$ and $18(3120+1 \mathrm{Kbdel} 8.6 \mathrm{~Kb})$ has been reported in Israeli Arab CF patients. ${ }^{15}$ Due to the methods used in our laboratories, we would not have detected this mutation among our patients. Although we have tested a small number of affected CF patients, our findings are consistent with 1548delG, $\Delta$ F508, and W1282X as common Arabic CF mutations. The mutations included in the current ACMG CF mutation screening panel

Table 3

Summary of mutations detected in previous studies among 93 unrelated Arabic CF patients (186 CF chromosomes)

\begin{tabular}{|c|c|c|}
\hline Mutation & $\begin{array}{l}\text { Total number of CF } \\
\text { chromosomes }\end{array}$ & $\begin{array}{c}\text { Allele } \\
\text { frequency }(\%)\end{array}$ \\
\hline$\Delta \mathrm{F}^{2} 08^{a}$ & 28 & 15.1 \\
\hline 1548delG & 24 & 13 \\
\hline $3120+1 \mathrm{G} \rightarrow \mathrm{A}^{a}$ & 21 & 11.3 \\
\hline I1234V & 19 & 10.2 \\
\hline $\mathrm{N} 1303 \mathrm{~K}^{a}$ & 10 & 5.4 \\
\hline $\mathrm{W} 1282 \mathrm{X}^{a}$ & 8 & 4.3 \\
\hline H139L & 7 & 3.8 \\
\hline 4010del4 & 4 & 2.2 \\
\hline G115X & 3 & 1.6 \\
\hline $711+1 \mathrm{G} \rightarrow \mathrm{A}$ & 3 & 1.6 \\
\hline S549R & 3 & 1.6 \\
\hline A141D & 2 & 1.1 \\
\hline R1177X & 2 & 1.1 \\
\hline S4X & 2 & 1.1 \\
\hline 2043delG & 2 & 1.1 \\
\hline $406-2 A \rightarrow G$ & 2 & 1.1 \\
\hline R75X & 1 & 0.5 \\
\hline 425del42 & 1 & 0.5 \\
\hline $1248+1 \mathrm{G} \rightarrow \mathrm{A}$ & 1 & 0.5 \\
\hline F533L & 1 & 0.5 \\
\hline $\mathrm{R} 553 \mathrm{X}^{a}$ & 1 & 0.5 \\
\hline $1811+2 \mathrm{~T} \rightarrow \mathrm{C}$ & 1 & 0.5 \\
\hline $2789+5 \mathrm{G} \rightarrow \mathrm{A}^{a}$ & 1 & 0.5 \\
\hline M952I & 1 & 0.5 \\
\hline 672delE & 1 & 0.5 \\
\hline $4096-285 \mathrm{G} \rightarrow \mathrm{A}$ & 1 & 0.5 \\
\hline No mutation detected & 36 & 19.4 \\
\hline
\end{tabular}

${ }^{a}$ Included in the ACMG recommended 23-mutation screening panel. 
which have been reported among Arabic CF patients $(\Delta \mathrm{F} 508$, $\mathrm{W} 1282 \mathrm{X}, \mathrm{N} 1303 \mathrm{~K}, 3120+1 \mathrm{G} \rightarrow \mathrm{A}, \mathrm{R} 553 \mathrm{X}$ and $2789+$ $5 \mathrm{G} \rightarrow \mathrm{A}$ ) account for only $37.1 \%$ of the mutations in this population. Using a Bayesian calculation and taking into account a 1 in 33 carrier frequency, the remaining carrier risk for an Arab-American is reduced to 1 in 52 following a negative CF test result using the current ACMG panel. Adding four mutations to a screening panel (1548delG, I1234V, H139L, and 4010del4) would increase the mutation detection rate to $66.3 \%$. Using a Bayesian calculation with this detection rate, a negative $\mathrm{CF}$ carrier screen would result in a residual CF carrier risk of 1 in 96 , a decrease of $46 \%$ compared to using only the current ACMG panel.

Genetic screening for $\mathrm{CF}$ is performed to provide an individual or couple with information regarding their risk of having a child with CF. Individuals with a negative result after CF carrier testing have a residual carrier risk calculated using a Bayesian analysis, which takes into account the population carrier frequency and mutation detection rate in the individual's race or ethnic background. These calculations can be performed for several populations, namely Caucasian, African-American, Hispanic, and Asian. Because the CF carrier frequency and mutation detection rate has not been well-established among the Arab-American population, no accurate residual risk can be provided to these individuals following a negative CF mutation screen. An additional challenge when counseling these patients arises due to the high incidence of consanguinity among this population, which increases the occurrence of autosomal recessive genetic diseases, such as CF. It is necessary to improve the interpretation of negative $\mathrm{CF}$ carrier screening results in this group to provide individuals with accurate information so that they can make informed reproductive decisions. Supplementation of the existing CF mutation panel has been suggested for other populations including African-Americans ${ }^{16}$ and Hispanic-Americans, ${ }^{17}$ and may also be helpful to laboratories screening a large number of ArabAmericans.

\section{References}

1. Kerem B, Rommens JM, Buchanan JA, Markiewicz D, et al. Identification of the cystic fibrosis gene: genetic analysis. Science 989;245:1073-1080.

2. Rommens JM, Iannuzzi MC, Kerem B, Drumm ML, et al. Identification of the cystic fibrosis gene: chromosome walking and jumping. Science 1989;245:1059-1065.

3. Riordan JR, Rommens JM, Kerem B, Alon N, et al. Identification of the cystic fibrosis gene: cloning and characterization of complementary DNA. Science 1989; 245:1066-1073.

4. Hospital for Sick Children. Toronto, Cystic Fibrosis Mutation Database. Available at: http://www.genet.sickkids.on.ca/cftr/. Accessed January 19, 2005.

5. American College of Obstetrics and Gynecology and American College of Medica Genetics. Preconception and prenatal carrier screening for Cystic Fibrosis, clinical and laboratory guidelines, 2001. American College of Obstetrics and Gynecology, Washington, DC; 2001

6. Watson MS, Cutting GR, Desnick RJ, Driscoll DA, et al. Cystic fibrosis population carrier screening: 2004 revision of American College of Medical Genetics mutation panel. Genet Med 2004;6:387-391.

7. Richards CS, Bradley LA, Amos J, Allitto B, et al. Standards and guidelines for CFTR mutation testing. Genet Med 2002;4:379-391.

8. Chillon M, Casals T, Mercier B, Bassas L, et al. Mutations in the cystic fibrosis gene in patients with congenital absence of the vas deferens. N Engl J Med 1995;332:14751480 .

9. Monaghan KG, Highsmith WE, Amos J, Pratt VM, et al. Genotype-phenotype correlation and frequency of the 3199del6 cystic fibrosis mutation among I148T carriers: results from a collaborative study. Genet Med 2004;6:421-425.

10. Rohlfs EM, Zhou Z, Sugarman EA, Heim RA, et al. The I148T CFTR allele occurs on multiple haplotypes: a complex allele is associated with cystic fibrosis. Genet Med 2002;4:319-323.

11. Mathew PM, Hamdan JA, Nazer H. Cystic fibrosis presenting with recurrent vomiting and metabolic alkalosis. Eur J Pediatr 1991;150:264-266.

12. Kambouris M, Banjar H, Moggari I, Nazer H, et al. Identification of novel mutations in Arabs with cystic fibrosis and their impact on the cystic fibrosis transmembrane regulator mutation detection rate in Arab populations. Eur J Pediatr 2000;159:303309 .

13. Desgeorges M, Megarbane A, Guittard C, Carles S, et al. Cystic fibrosis in Lebanon: distribution of CFTR mutations among Arab communities. Hum Genet 1997;100: 279-283.

14. el-Harith EA, Dork T, Stuhrmann M, Abu-Srair H, al-Shahri A, et al. Novel and characteristic CFTR mutations in Saudi Arab children with severe cystic fibrosis. J Med Genet 1997;34:996-999.

15. Lerer I, Laufer-Cahana A, Rivlin JR, Augarten A, et al. A large deletion mutation in the CFTR gene $(3120+1 \mathrm{Kbdel} 8.6 \mathrm{~Kb})$ : a founder mutation in the Palestinian Arabs. Mutation in brief no. 231. Online. Human Mutation 1999;231.

16. Monaghan KF, Bluhm D, Philips M, Feldman GL. Preconception and prenatal cystic fibrosis carrier screening of African Americans reveals unanticipated frequencies for specific mutations. Genet Med 2004;6:141-144.

17. Schrijver I, Ramalingam S, Sankaran R, Swanson S, et al. Diagnostic testing by CFTR gene mutation analysis in a large group of Hispanics. J Mol Diagn 2005;7:289-299. 